\title{
EDITORIAL
}

\section{El futuro de la investigación en la universidad pública peruana}

Pedro Miguel Barrientos Felipa ${ }^{1}$

La ley $\mathrm{N}^{\circ} 30220$, que norma la creación, funcionamiento, supervisión y cierre de la universidades, sean públicas o privadas, define a la universidad en su Artículo 3 como "una comunidad académica orientada a la investigación y a la docencia, que brinda una formación humanista, científica y tecnológica con una clara conciencia de nuestro país como realidad multicultural". En el Artículo 48 se menciona que "la investigación constituye una función esencial y obligatoria de la universidad, que la fomenta y realiza, respondiendo a través de la producción de conocimiento y desarrollo de tecnologías a las necesidades de la sociedad".

La Universidad Nacional Mayor de San Marcos es parte de la respuesta al desafío que implica investigar en la universidad, considerando que en el contexto anterior a la nueva ley universitaria la investigación en instituciones académicas, en especial las públicas, investigar era una función limitada de las universidades. Tal como hoy la explicita la ley $\mathrm{N}^{\circ}$ 30220 (Artículo 7) se debe asumir este compromiso que implica dejar más de cuarenta años sin incentivos a la investigación universitaria, en donde los profesores y alumnos son el soporte de esta realización, lo que beneficia al país, toda vez que investigar significa generar nuevo conocimiento. La investigación permite a los jóvenes estudiantes ampliar su capacidad de análisis, su acuciosidad para tener vivo el espíritu del nuevo conocimiento que le es útil cuando está realizando su actividad laboral.

\footnotetext{
${ }^{1}$ Economista. Vicedecano de Investigación y Posgrado de la Facultad de Ciencias Económicas de la UNMSM. Doctor en Administración de Negocios Globales. Profesor principal de la Facultad de Ciencias Económicas. Director de la Revista Pensamiento Crítico. Dirección de correspondencia: Calle Germán Amézaga 375, Cercado, Lima, Perú. Correo electrónico: pbarrientosf@unmsm.edu.pe
} 
Este comportamiento origina una desconexión de la universidad con la institucionalidad privada y pública, siendo la consecuencia el letargo de la innovación, la que pudo subsistir a través de instituciones de investigación y algunas universidades privadas, que fueron como una pequeña luz en la oscuridad de la falta de nuevo conocimiento. Esto genera un efecto de desconfianza en la sociedad peruana, hacia la universidad pública, considerando que en los momentos actuales, en un proceso de evaluación continua de las universidades y el tener un lugar que apoye la indicación de una universidad como bien calificada no lo hace posible. Cuando se lee los rankings universitarios internacionales la universidad pública peruana aparece rezagada considerando su potencialidad, lo que influye en el ánimo de los estudiantes.

Ahora, la universidad de caminar rápido para lograr ubicarse en los primeros lugares, que es el sitial que le corresponde. En este tránsito se encuentra la Universidad Nacional Mayor de San Marcos, porque comprende que investigar es parte de la vida universitaria y su realización es una muestra del aporte hacia la sociedad. Es una tarea, compromiso de los profesores, para iniciar a sus alumnos en el proceso de investigación. Su realización es la que genera nuevos conocimientos y marca el camino que el país debe transitar hacia su desarrollo. Por eso es que el Estado debe brindar el apoyo posible a través de recursos financieros, equipos y personas capaces de cumplir tal función. Los alumnos, la fuerza que da vida a la universidad, son el combustible que Perú necesita, son las personas que deben asumir su compromiso con criterios de objetividad y firmeza y el aprendizaje acerca de qué es investigar y cómo aplicarlo es un conocimiento valioso.

La adquisición de nuevas experiencias para generar conocimiento estimula a ser críticos con fundamentos consistentes ante una realidad, permite ser creativo para generar soluciones necesarias, convierte a los novatos investigadores en amantes de las nuevas ideas y en renovados de las actuales. Todo ese nuevo conocimiento lo volcará a las oportunidades laborales que se le presentan otorgando así los beneficios que la universidad le apoyo para que en la postrimería lo comparta. Del apoyo a la investigación depende el mejor manejo de todo país. Los países que están adelante basan su ventaja en el apoyo que le otorga a la investigación. 
Los artículos que se incluyen en este número, son en su totalidad arbitrados. La publicación se inicia con el escrito de Alexci Igor Chong Ríos, "Inversión Extranjera Directa y Productividad en el Perú: 2016 2017". A continuación Eric Espinoza Campos con "Gestión de Riesgos de Desastres en Albergues en el distrito del Rímac". Se incluye también a los profesores Milagros Rosario Quispe Quispe y Richard Hernán Roca Garay con "Determinantes de la pobreza en el Perú bajo el enfoque de activos". Está la contribución de Juan Celestino León Mendoza con "Efectos de la Desnutrición en el Rendimiento Escolar de los Niños en el Perú”. Asimismo, se publica el artículo de Elsa Luz Yactayo Chávez, "La ejecución presupuestal de Essalud del Perú como un instrumento de gestión". Jesús Lechuga Montenegro y Faustino Vega Miranda ponen a disposición "Miradas de la crisis contemporánea: la Gran Recesión 2008-2009”. Asimismo, participan María Josefina León León, Juan Carlos Hurtado Ramos y César D. Alvarado Gutiérrez, "La segregación de la política fiscal en el esquema de las metas de inflación". Se completa con el artículo de los investigadores Jairo Beymar Céspedes López y Remy Silvia Martínez Pairo, "Análisis del mercado de valores como alternativa de financiamiento para las PYMES en Latinoamérica" 
